\title{
Body composition of table tennis players: comparison between performance level and gender
}

\author{
Alessandro Moura Zagatto ${ }^{1,3}$ - Fabio Milioni ${ }^{1,3} \cdot$ Ismael Fortes Freitas $^{2,3} \cdot$ \\ Sérgio Alves Arcangelo ${ }^{1} \cdot$ Johnny Padulo ${ }^{4,5}$
}

Received: 24 October 2015/Accepted: 26 November 2015/Published online: 15 December 2015

(C) Springer-Verlag Italia 2015

\begin{abstract}
The purpose of this study was to compare wholebody and segmental body composition variables of trained Brazilian table tennis players, according to different performance levels and gender. Sixty-four table tennis players (45 male and 19 female) were distributed in three groups according to performance level: international level players (ILP; 12 male; 8 female), national level players (NLP; 14 male; 6 female) and regional level players (RLP; 19 male; 5 female). The anthropometry measurements and body composition analysis were performed using Dual energy X-ray absorptiometry. Male players demonstrated higher fat-free mass (FFM), and lower fat mass $(\mathrm{FM})$ and body fat percentage $(\% \mathrm{BF}, p<0.05)$ compared to female players in all competitive levels, however, non-significant differences were found between whole-body composition and performance level. In the comparison between the dominant and non-dominant arms, FFM, fat-free soft tissue mass (FFSTM) and bone mineral density (BMD) were higher in the dominant arm $(p<0.05)$ compared to the non-dominant arm in all competitive levels, however, the male
\end{abstract}

Alessandro Moura Zagatto

azagatto@yahoo.com.br

1 Departamento de Educação Física, Faculdade de Ciências de Bauru, UNESP, Universidade Estadual Paulista, Avenida Engenheiro Luiz Edmundo Carrijo Coube, Vargem Limpa, Caixa-Postal: 549, Bauru, São Paulo 17033360, Brazil

2 Faculty of Sciences and Tecnology, UNESP, Universidade Estadual Paulista, Presidente Prudente, São Paulo, Brazil

3 Post Graduate Program of Human Movement Science, Department of Physical Education, UNESP, Universidade Estadual Paulista, Rio Claro, São Paulo, Brazil

4 University e-Campus, Novedrate (CO), Italy

5 SPO Sport Performance Optimization Lab, CNMSS, Tunis, Tunisia
ILP group presented lower FFM and FFSTM in the dominant arm compared to the NLP, while the female ILP group presented higher BMD compared to the NLP and RLP. In conclusion, male table tennis players presented higher FFM and lower $\mathrm{FM}$ and \%BF than female players and the dominant arm presented higher FFM and BMD than the non-dominant, possibly due to the mechanical impact-load imposed by time of table tennis practice.

Keywords Body Composition - Bone mineral density · Fat-free mass - Fat mass $\cdot$ Table tennis player

\section{Introduction}

Table tennis is considered an intermittent sport involving high activity of the lower and upper limbs during competitions [1, 2]. Particularly, table tennis is characterized as an endurance intensive effort, but with an important contribution from the a-lactic energy system during the repeated high-intensity efforts [1, 2]. Regarding muscle performance, a table tennis player is not required to produce high levels of muscular force (i.e., just general body strength) but does need developed motor control [1, 2].

In this way, body composition could be considered an important parameter to assess sports performance. The assessment of anthropometric measures are widely used for many purposes, such as talent identification [3] and monitoring the development of muscle mass, which could contribute to improvement in body movement and metabolic demand [4]. Furthermore, regarding racket sports, the long term training can act as an important osteogenic factor, especially for players who practice for many years, causing member asymmetry of fat-free mass and bone mineral content between the dominant and non-dominant 
limbs [5]. In tennis, which is also a racket-sport, significant differences between bone mass density of adolescent female players and non-tennis players (in lumbar spine and total hip bone mass) were observed by Ermin et al. [6].

Despite the great importance of body composition in sports performance, to date, only a few studies have documented the body composition of table tennis players and the majority of these only characterized the somatotype through the measurement of body weight, height and the sum of skinfolds $[7,8]$. To our knowledge no studies have investigated the body composition of table tennis players using advanced techniques (i.e., dual energy X-ray absorptiometry technique) and even fewer the impact of performance level and gender on body composition; this represents a huge gap in the literature.

Therefore, the purpose of this study was to compare the whole-body and segmental body composition variables in Brazilian trained table tennis players according to different performance levels and gender.

\section{Materials and methods}

\section{Subjects}

Sixty-four trained Brazilian table tennis players [ 45 male (aged $24 \pm 7$ years, height $176.8 \pm 3.0 \mathrm{~cm}$, weight $71.8 \pm 11.3 \mathrm{~kg}$ and body mass index $23.4 \pm 2.3 \mathrm{~kg} / \mathrm{m}^{2}$ ) and 19 female (aged $23 \pm 6$ years, height $164.45 \pm 6.3 \mathrm{~cm}$, weight $58.7 \pm 9.5 \mathrm{~kg}$ and BMI $21.6 \pm 2.6 \mathrm{~kg} / \mathrm{m}^{2}$ )] took part in this study. The sample was divided into three groups: international level (ILP-players ranked by the International Table Tennis Federation, ITTF; 12 male and 8 female), national level (NLPplayers with national experience but not ranked by the ITTF; 14 male and 6 female) and regional level (RLP - players with regional experience; 19 male and 5 female). The players presented an average of $11.7 \pm 5.9$ years of training experience and a training frequency of $4.3 \pm 1.5$ times per week. Prior to participation, all subjects were informed of the risks and benefits and signed an informed consent term according to the Helsinki declaration. In addition, all experimental procedures were approved by the Ethical Committee of FCT/UNESP (Protocol number 07/2009).

All data were collected before the beginning of an Official Table Tennis Championship in the City of Bauru, São Paulo State, Brazil. The body composition assessment was performed on a free-day without training.

\section{Body composition measurement using dual energy X-ray absorptiometry (DXA)}

Weight $(\mathrm{kg})$ and height $(\mathrm{m})$ were measured for each participant, and the body mass index was calculated using the formula weight $/ \mathrm{height}^{2}\left(\mathrm{~kg} / \mathrm{m}^{2}\right)$. To assess the bone mineral content, fat mass, and lean mass, the dual energy X-ray absorptiometry technique (DXA Discovery, Hologic ${ }^{\circledR}$, USA) was performed with a Hologic Discovery total body scan, fan-beam densitometer, software QDR for Windows version 12.5 (Hologic, Waltham, Massachusetts, USA). The radiation exposure during the DXA procedure was less than $0.05 \mathrm{mRem}(0.5 \mathrm{~Sv})$, which means an exposure 50 times lower than that of an X-ray examination. Following the protocol for DXA described by the manufacturer, a step phantom with six fields of acrylic and aluminum of varying thickness and known absorptive properties was scanned to serve as an external standard for the analysis of different tissue components. This procedure has been validated for general DXA use [9]. The DXA Discovery, Hologic ${ }^{\circledR}$ (USA) has a low coefficient of variation (bone mineral content $=0.6 \%$, fat-free soft tissue $=0.3 \%$, fat mass and percentage body fat $=2.5 \%$ ) [10].

The method estimates the body composition by dividing the body into three anatomic compartments: fat-free mass, fat mass and bone mineral content. The results are presented in grams of fat-free mass (FFM), fat mass (FM), fatfree soft tissue mass (FFSTM) and bone mineral content (BMC). The body fat percentage (\%BF) was expressed as a percentage of the total, according to dominant and nondominant arms. The bone mineral density (BMD) is presented in $\mathrm{g} / \mathrm{cm}^{2}$.

The segmental body composition was determined from the regional analysis of the whole-body. The limbs were assessed by separating the arms from the trunk by an inclined line crossing the scapulohumeral joint, and the legs separated from the hip by an inclined line crossing the hip joint.

\section{Statistical analysis}

The results were expressed as mean \pm standard deviation. Initially the normality of the data was analyzed using the Shapiro-Wilk test. Next, the data were analyzed using the two-way analysis of variance (ANOVA) (gender $\times$ performance level), followed of the Bonferroni post hoc test. To compare dominant and non-dominant arms within the group the paired $t$ test was used. In all cases, statistical significance was set at $p<0.05$. Statistical analyses were performed using the software package SPSS version 16.0 (SPSS Inc., Chicago, IL, USA).

\section{Results}

Table 1 shows the whole body composition according to gender and performance level. 
Table 1 Whole body composition according gender and performance level for the international (ILP), national (NLP) and regional (RLP) players

\begin{tabular}{|c|c|c|c|c|c|c|c|}
\hline & \multicolumn{3}{|l|}{ Male } & \multicolumn{3}{|l|}{ Female } & \multirow[t]{2}{*}{$p$ value $(1-\beta)$} \\
\hline & $\operatorname{ILP}(N=12)$ & $\operatorname{NLP}(N=14)$ & $\operatorname{RLP}(N=19)$ & $\operatorname{ILP}(N=8)$ & $\operatorname{NLP}(N=6)$ & $\operatorname{RLP}(N=5)$ & \\
\hline \multicolumn{8}{|l|}{ Total } \\
\hline Age (years) & $21.6 \pm 5.6$ & $25.8 \pm 7.0^{@}$ & $20.8 \pm 5.3^{*}$ & $19.3 \pm 4.2^{@}$ & $23.5 \pm 4.5$ & $27.4 \pm 5.9$ & $0.03(1-\beta=0.77)$ \\
\hline TE (years) & $10.5 \pm 5.6$ & $13.5 \pm 5.2^{@}$ & $8.6 \pm 4.9^{*}$ & $10.0 \pm 4.6^{\S @}$ & $16.7 \pm 5.4$ & $16.4 \pm 7.5$ & $0.008(1-\beta=0.8874)$ \\
\hline $\begin{array}{c}\text { TF (times/ } \\
\text { week) }\end{array}$ & $5.0 \pm 1.0^{@}$ & $4.2 \pm 1.3$ & $4.0 \pm 1.6$ & $5.4 \pm 0.7^{\S @}$ & $3.7 \pm 1.6$ & $3.2 \pm 1.8$ & $0.03(1-\beta=0.78)$ \\
\hline Height (cm) & $171.1 \pm 5.5^{* \S @}$ & $175.1 \pm 6.8^{*}$ & $177.3 \pm 8.3^{*}$ & $164.9 \pm 6.1$ & $163.7 \pm 6.0$ & $164.5 \pm 8.0$ & $0.000(1-\beta=1.00)$ \\
\hline $\begin{array}{l}\text { Body Mass } \\
\text { (kg) }\end{array}$ & $67.1 \pm 8.7 *$ & $72.7 \pm 13.1^{*}$ & $74.2 \pm 10.9^{*}$ & $57.6 \pm 13.3$ & $62.1 \pm 5.7$ & $56.2 \pm 5.3$ & $0.003(1-\beta=0.96)$ \\
\hline BMI $\left(\mathrm{kg} / \mathrm{m}^{2}\right)$ & $22.8 \pm 1.9$ & $23.6 \pm 2.7$ & $23.5 \pm 2.3$ & $21.0 \pm 3.3$ & $23.2 \pm 1.5$ & $20.8 \pm 1.7$ & $0.076(1-\beta=0.66)$ \\
\hline $\mathrm{BMC}(\mathrm{kg})$ & $2.4 \pm 0.3^{*}$ & $2.7 \pm 0.4^{*}$ & $2.4 \pm 0.5^{*}$ & $2.6 \pm 0.3$ & $2.2 \pm 0.3$ & $2.2 \pm 0.5$ & $0.000(1-\beta=1.00)$ \\
\hline $\begin{array}{c}\mathrm{BMD}(\mathrm{g} / \\
\left.\mathrm{cm}^{2}\right)\end{array}$ & $1.14 \pm 0.07^{*}$ & $1.19 \pm 0.08 *$ & $1.12 \pm 0.09$ & $1.16 \pm 0.06$ & $1.09 \pm 0.07$ & $1.06 \pm 0.13$ & $0.004(1-\beta=0.93)$ \\
\hline FFM (kg) & $58.5 \pm 6.2 *$ & $62.3 \pm 10.3 *$ & $63.2 \pm 8.4^{*}$ & $44.5 \pm 7.1$ & $44.6 \pm 5.1$ & $43.4 \pm 3.5$ & $0.000(1-\beta=1.00)$ \\
\hline FM (kg) & $8.6 \pm 2.9^{*}$ & $10.4 \pm 3.6^{*}$ & $10.9 \pm 4.5$ & $13.1 \pm 6.6$ & $17.5 \pm 2.4$ & $12.8 \pm 2.9$ & $0.177(1-\beta=0.51)$ \\
\hline FFSTM (kg) & $56.1 \pm 6.2^{*}$ & $59.6 \pm 10.4^{*}$ & $60.8 \pm 8.4^{*}$ & $41.9 \pm 7.0$ & $42.4 \pm 5.0$ & $41.3 \pm 2.4$ & $0.000(1-\beta=1.00)$ \\
\hline$\% \mathrm{BF}$ & $12.6 \pm 2.9^{*}$ & $14.1 \pm 3.3^{*}$ & $14.4 \pm 4.8^{*}$ & $21.9 \pm 5.0$ & $28.3 \pm 3.4$ & $22.6 \pm 3.6$ & $0.000(1-\beta=1.00)$ \\
\hline
\end{tabular}

$T E$ training experience, $T F$ training frequency, $B M I$ body mass index, $B M C$ bone mineral content, $B M D$ bone mineral density, $F F M$ fat-free mass, FFSTM fat-free soft tissue mass, $\% B F$ body fat percentage

$* p<0.05$ compared to the same performance level female group

$\S p<0.05$ compared to the same gender in national level

@ $p<0.05$ compared to the same gender in regional level

In general, for the whole body composition outcomes, significant differences were found between genders in all variables $(p<0.004 ; 1-\beta>0.927)$, except BMI. However, a non-statistically significant difference was found among performance levels within the same gender $(p>0.05)$.

The comparisons of FFM, FFSTM and BMD between dominant and non-dominant arms according to performance level, demonstrated significant differences in all variables between the male and female genders $(p<0.001$; $1-\beta>0.99$ ) (Table 2).

The interaction showed that the female ILP group presented higher FFM $(p<0.001)$ and BMD in the dominant arm $(p<0.001)$ when compared to the other female groups. The male ILP group presented higher FFM $(p<0.05)$ and FFSTM $(p<0.05)$ for the dominant arm compared to the non-dominant. The male ILP group presented lower FFM for the dominant arm $(p<0.001)$ when compared to the NLP.

The dominant arm presented significantly higher FFM, FFSTM and BMD $(p<0.001)$ in all performance levels and also in male compared to female players of the same level.

\section{Discussion}

The aim of the present study was to compare the wholebody and segmental body composition variables in trained Brazilian table tennis players according to different performance levels and gender. The main findings were that there is a difference for almost all whole-body analysis between genders in the same performance level, but no difference between performance levels in the same gender. Male players presented higher FFM, FM and lower \%BF than females in all competitive levels. The dominant arm (i.e., racket arm), non-dominant arm and leg FFM and FFSTM were higher in males compared to females and FFM, FFSTM and BMD were higher in the dominant arm when compared to the non-dominant arm in all competitive levels and both genders.

Body composition is a very important parameter of sports performance, since an excess of FM can act as "dead weight" in modalities in which body mass needs to be lifted repeatedly against gravity or moved as fast as possible [4], such as in table tennis. Although anthropometric measures and body composition have been widely investigated as a variable of sport talent identification $[11,12]$ in 


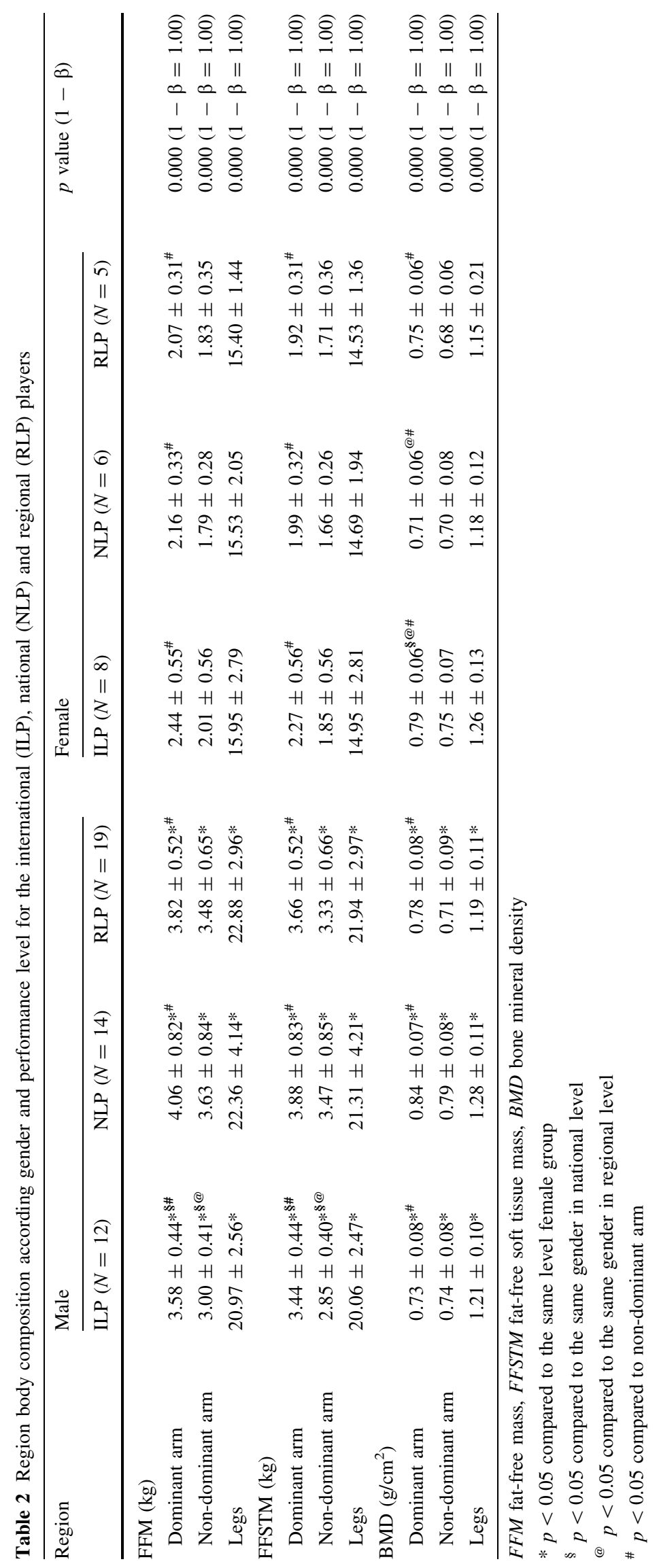


addition to being used to classify different physical activity levels [4], to our knowledge there are no published studies which compare body composition parameters of table tennis players of different competitive levels and genders.

The athletes of the present study presented similar values for age, body mass and height to other published studies [13]. Possibly the absence of significant differences between the competition levels occurred due to the age and characteristics of our sample (i.e., adult players) who presented long-term experience of training (12.6 \pm 3.4 years). This may suggest that anthropometric characteristics are parameters that exert influence on achieving a high performance level and point to body composition as an important parameter for talent identification in childhood and adolescence.

The male players presented higher whole and segmental FFM and FFSTM compared to the females of the same level in all groups (i.e., international, national and regional players). These are expected results since adult males usually present higher muscle mass. Carrasco et al. [7, 14] observed higher FM and \% BF for females and, in contrast to the current study, these authors did not find significant differences in FFM between genders, maybe due to the fact that their samples were composed of young table tennis table players (i.e., $\approx 12$ years old) with a high influence of the pubertal period. High values of FM and \%BF, mainly localized in the lower limbs, could act as an "over load" becoming an important restrictive factor to performing rapid movements and changes of direction, acceleration and deceleration; characteristic table tennis actions [15]. In addition, in the study of Carrasco et al. [14], the body composition was measured using skinfolds while in the present study body composition was measured using the X-ray method (DXA-scan).

In the dominant arm, FFM, FFSTM and BMD presented higher values for males and females, compared to the nondominant arm, for all performance levels. The long-term practice of racket sports such as tennis and table tennis seems to induce an important osteogenic effect on the arm (humerus) and forearm (radius and ulna) bones and an increase in muscle mass due to the mechanic impactloading characteristic [5, 16-20]. Sanchis-Moysi et al. [5] showed an inter-arm asymmetry in young tennis players with higher BMD and FFM in the dominant compared to the non-dominant arm, and verified that the magnitude is directly dependent on the training volume. In the present study, higher values of BMD in the dominant arm were verified in the female ILP group than in the other groups probably due to the significantly higher volume and intensity of training (Table 1).

In summary, to our knowledge, the present study is the first to present anthropometric and body composition characteristics of adult table tennis players of different performance levels. Male table tennis players presented higher whole FFM and lower FM and \%BF than female table tennis players; the dominant arm showed higher FFM, FFSTM and BMD compared to the non-dominant arm in both male and female players. However, there were no significant differences between genders of adult tennistable players. This indicates that anthropometric and body composition parameters could be important for talent identification but ineffective for classifying the performance level of adult players. In addition to the relevance of the findings the main limitation that could be highlighted is that this study assessed only Brazilian table tennis players, and further studies should be performed with athletes of different nationalities.

\section{Compliance with ethical standards}

Conflicts of interest There are no conflicts of interest in this paper.

Ethical procedures The study was approved by the Ethics Committee on Human Research of the Universidade Estadual Paulista, UNESP, Process Number 07/2009.

Informed consent Informed consent was obtained from all individual participants included in the study.

Grant No grant support was provided for the present study.

\section{References}

1. Zagatto AM, Morel EA, Gobatto CA (2010) Physiological responses and characteristics of table tennis matches determined in official tournaments. J Strength Cond Res 24(4):942-949. doi: $10.1519 / \mathrm{Jsc} .0 \mathrm{~b} 013 \mathrm{e} 3181 \mathrm{cb} 7003$

2. Kondric M, Zagatto AM, Sekulic D (2013) The physiological demands of table tennis: a review. J Sports Sci Med 12(3):362-370

3. Pion J, Segers V, Fransen J, Debuyck G, Deprez D, Haerens L, Vaeyens R, Philippaerts R, Lenoir M (2015) Generic anthropometric and performance characteristics among elite adolescent boys in nine different sports. Eur J Sport Sci 15(5):357-366. doi:10.1080/17461391.2014.944875

4. Hogstrom GM, Pietilo T, Nordstrom P, Nordstrom A (2012) Body composition and performance: influence of sport and gender among adolescents. J Strength Cond Res 26(7):1799-1804. doi:10.1519/Jsc.0b013e318237e8da

5. Sanchis-Moysi J, Dorado C, Olmedillas H, Serrano-Sanchez JA, Calbet JAL (2010) Bone and lean mass inter-arm asymmetries in young male tennis players depend on training frequency. Eur $\mathbf{J}$ Appl Physiol 110(1):83-90. doi:10.1007/s00421-010-1470-2

6. Ermin K, Owens S, Ford MA, Bass M (2012) Bone mineral density of adolescent female tennis players and nontennis players. J Osteoporos 2012:423910. doi:10.1155/2012/423910

7. Carrasco L, Pradas F, Martínez A (2010) Somatotype and body composition of young top-level table tennis players. Int $\mathbf{J}$ Table Tennis Sci 6:175-177

8. Munivrana G, Paušić J, Kondrič M (2011) The influence of somatotype on young table tennis players' competitive success. Kinesiologia Slovenica 1(17):42-51 
9. Tataranni PA, Ravussin E (1995) Use of dual-energy X-RAY absorptiometry in obese individuals. Am J Clin Nutr 62(4):730-734

10. Bilsborough JC, Greenway K, Opar D, Livingstone S, Cordy J, Coutts AJ (2014) The accuracy and precision of DXA for assessing body composition in team sport athletes. J Sports Sci 32(19):1821-1828. doi:10.1080/02640414.2014.926380

11. Mala L, Maly T, Zahalka F, Bunc V, Kaplan A, Jebavy R, Tuma M (2015) Body composition of elite female players in five different sports games. J Hum Kinet 45:207-215. doi:10.1515/ hukin-2015-0021

12. Pion J, Lenoir M, Vandorpe B, Segers V (2015) Talent in female gymnastics: a survival analysis based upon performance characteristics. Int J Sports Med. doi:10.1055/s-0035-1548887

13. Zagatto A, Miranda MF, Gobatto CA (2011) Critical power concept adapted for the specific table tennis test: comparisons between exhaustion criteria, mathematical modeling, and correlation with gas exchange parameters. Int $\mathrm{J}$ Sports Med 32(7):503-510. doi:10.1055/s-0030-1270470

14. Carrasco L, Pradas F, Torre A, Rapún M, Martínez P (2011) Anthropometric profile of international young table tennis players. Int J Table Tennis Sci 7:30-31

15. Nikolic I, Nikolic I, Furjan-Mandic G, Kondric M (2014) The relationship of morphology and motor abilities to specific table tennis tasks in youngsters. Coll Antropol 38(1):241-245
16. Kontulainen S, Kannus P, Haapasalo H, Heinonen A, Sievanen H, Oja P, Vuori I (1999) Changes in bone mineral content with decreased training in competitive young adult tennis players and controls: a prospective 4-yr follow-up. Med Sci Sports Exerc 31(5):646-652

17. Kontulainen S, Sievanen H, Kannus P, Pasanen M, Vuori I (2003) Effect of long-term impact-loading on mass, size, and estimated strength of humerus and radius of female racquet-sports players: a peripheral quantitative computed tomography study between young and old starters and controls. J Bone Miner Res 18(2):352-359. doi:10.1359/jbmr.2003.18.2.352

18. Kontulainen S, Sievanen H, Kannus P, Pasanen M, Vuori I (2002) Effect of long-term impact-loading on mass, size, and estimated strength of humerus and radius of female racquet-sports players: a peripheral quantitative computed tomography study between young and old starters and controls. J Bone Miner Res 17(12):2281-2289. doi:10.1359/jbmr.2002.17.12.2281

19. Sanchis-Moysi J, Dorado C, Olmedillas H, Serrano-Sanchez JA, Calbet JA (2010) Bone mass in prepubertal tennis players. Int J Sports Med 31(6):416-420. doi:10.1055/s-0030-1248331

20. Sanchis-Moysi J, Idoate F, Dorado C, Alayon S, Calbet JA (2010) Large asymmetric hypertrophy of rectus abdominis muscle in professional tennis players. PLoS ONE 5(12):e15858. doi:10. 1371/journal.pone.0015858 